\title{
Numerical Prediction of Strong Wind Induced by Topographic Effect
}

\section{Takanori Uchida}

Research Institute for Applied Mechanics (RIAM), Kyushu University, Kasuga, Fukuoka, Japan

Email: takanori@riam.kyushu-u.ac.jp

How to cite this paper: Uchida, T. (2019) Numerical Prediction of Strong Wind Induced by Topographic Effect. Open Journal of Fluid Dynamics, 9, 224-240. https://doi.org/10.4236/ojfd.2019.93015

Received: July 16, 2019

Accepted: August 16, 2019

Published: August 19, 2019

Copyright $\odot 2019$ by author(s) and Scientific Research Publishing Inc. This work is licensed under the Creative Commons Attribution International License (CC BY 4.0).

http://creativecommons.org/licenses/by/4.0/ (c) (i) Open Access

\begin{abstract}
This paper describes the numerical study of nonstratified airflow over a real complex terrain. Attention is focused on the mechanism of a local strong wind induced by a topographic effect. In order to clarify the mechanism of the occurrence of strong winds accompanied by the effects of terrain, the use of a numerical simulation is very effective, in which conditions can be set without the influence of ground roughness and temperature distribution. As a result, airflow converged to a small basin of mountain terrain in the upper stream, and local strong wind was generated leeward along the slope of the mountain terrain. Furthermore, the influence of the reproduction accuracy of geographical features, that is, horizontal grid resolution, was examined. Consequently, to reproduce the above-mentioned local strong wind, it was shown that horizontal grid resolution from $50 \mathrm{~m}$ to about $100 \mathrm{~m}$ was necessary.
\end{abstract}

\section{Keywords}

CFD, LES, Complex Terrain, Local Strong Wind, Topographic Effect, Grid Resolution

\section{Introduction}

The author et al. have been developing a nonstationary and nonlinear wind-synopsis simulator (large-eddy simulation (LES) turbulence model) applicable to analyses of wind synopsis and the diffusion fields of any complex and steep terrain in the world which is called the Research Institute for Applied Mechanics, Kyushu University, COM putational Prediction of Airflow over Complex Terrain (RIAM-COMPACT) [1]-[16]. The analysis space is focused on a narrow range from several hundred meters to several kilometers, and it is possible to numerically predict the topographic effects of winds with high accuracy, such as flow separation and the formation of reverse-flow regions caused by that, 
local increase of flow speed, and the reattachment of a separated shear layer.

Typhoon Tokage (0423) approached Kyushu, Japan, on 20 October 2004. Even though it did not make landfall in Kyushu, the range of its strong winds covered a wide area, and Ogimachi (Ogi City at present, hereafter referred to as Ogimachi) in Saga Prefecture suffered extensive damage (Figure 1). The direction of the wind of Typhoon 0423 at the time when it caused the damage was from northwest to north-northwest, and if the geographical features surrounding the area are considered, the influence of the Tenzan Mountains located on the north side of Ogimachi is supposed to have been great. In other words, it is supposed that the strong winds of the typhoon were further strengthened due to local geographical features and, as a result, the damage from the strong winds was greatly amplified [17]-[28]. In order to clarify the mechanism of the occurrence of strong winds accompanied by the effects of terrain, the use of the numerical simulation is very effective, in which conditions can be set without the influence of ground roughness and temperature distribution.

In this research, two tasks were investigated and discussed using the RIAM-COMPACT method described above. A task was to conduct a numerical simulation in a broad range targeting the north-northwest wind direction in order to clarify the mechanism of the strong-wind phenomenon that occurred around Ogimachi. Another task was to investigate the reproducibility of regional-scale terrains, in other words, the effect of horizontal grid resolution on calculation results.

The structure of this paper is as follows. Chapter 2 explains the numerical calculation method. Chapter 3 explains wind-velocity data record when Typhoon 0423 was passing through. Chapter 4 explains calculation results and discussion. Chapter 5 explains the effect of horizontal grid resolution on calculation results. Finally, Chapter 6 is the conclusion.

\section{LES by Finite-Difference Method Based on Collocated Grid of Generalized Curvilinear Coordinate System}

The numerical calculation method, calculation areas, and boundary conditions are described here. In order to numerically predict wind flows over a complex terrain with a high degree of accuracy, avoiding unstable oscillations, a collocated grid of generalized curvilinear coordinates was used. The collocated grid here is a grid system in which physical velocity components and pressure were defined in the cell centers of the calculation grid, and the variables of contravariant velocity components multiplied by Jacobian are defined in the cell interface. The numerical calculation method was conducted based on the finite-difference method (FDM), and the large-eddy simulation (LES) was conducted. For the governing equations of the flow, a filtered continuity equation for incompressible fluid (Equation (1)) and a filtered Navier-Stokes equation (Equation (2)) were used.

$$
\frac{\partial \bar{u}_{i}}{\partial x_{i}}=0
$$



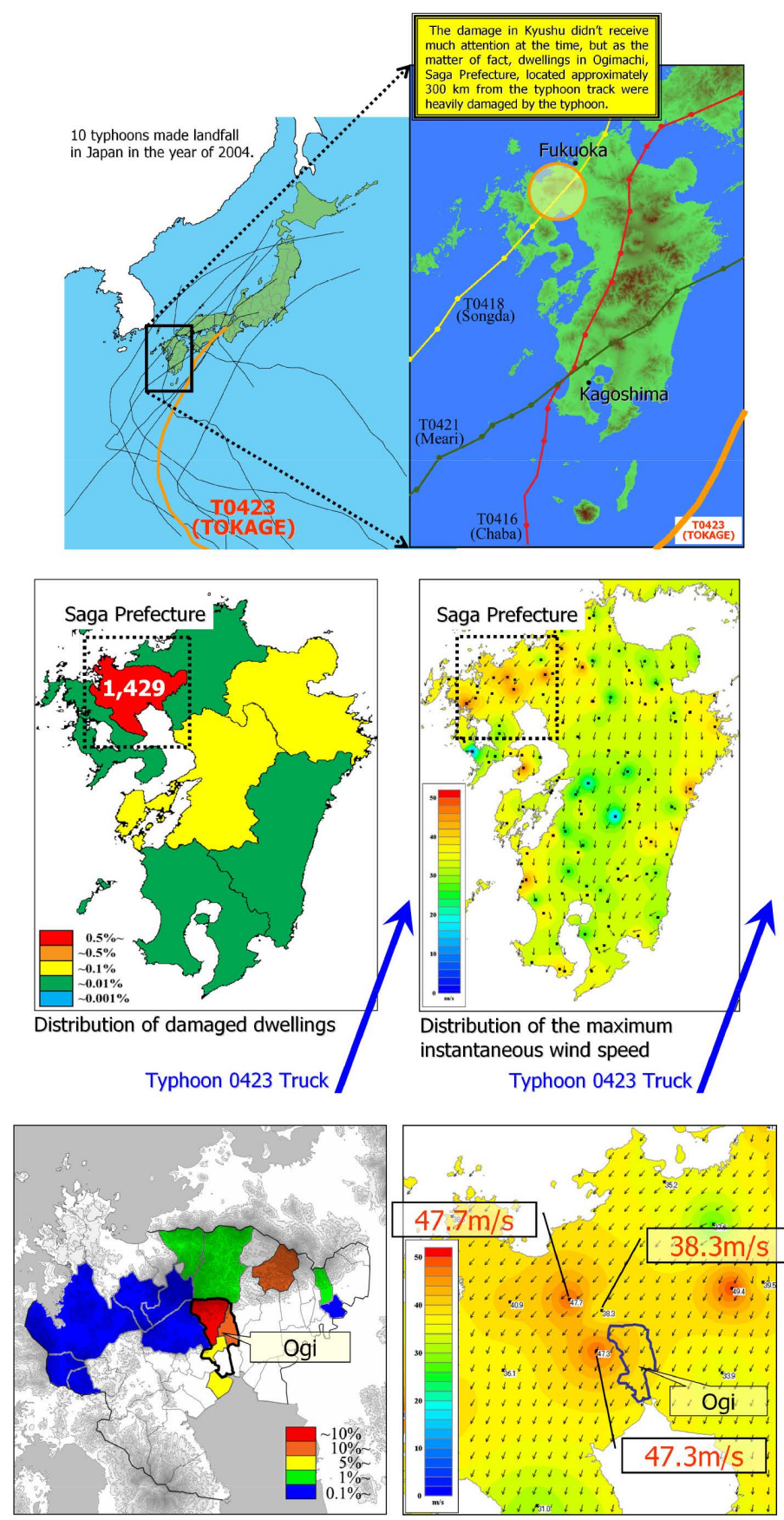

Distribution of damaged dwellings

Distribution of the maximum instantaneous in Saga Prefecture wind speed in Saga Prefecture

Figure 1. Disasters caused by strong winds targeted by this research.

$$
\frac{\partial \bar{u}_{i}}{\partial t}+\bar{u}_{j} \frac{\partial \bar{u}_{i}}{\partial x_{j}}=-\frac{\partial \bar{P}}{\partial x_{i}}+\frac{1}{\operatorname{Re}} \frac{\partial^{2} \bar{u}_{i}}{\partial x_{j} \partial x_{j}}-\frac{\partial \tau_{i j}}{x_{j}}
$$

The calculation algorithm was based on the fractional step (F-S) method [29], and the time-marching method was based on the Euler explicit method. Poisson's equation was solved by the successive over-relaxation (SOR) method. All discretizations of the terms of space were based on a second-order cen- 
tral-difference scheme except for the convection term of Equation (2). The term of convection was based on third-order upwind difference scheme by Kajishima [30]. For the numerical diffusion coefficient due to third-order upwind difference scheme, 0.5 is used as opposed to 3.0 from the Kawamura-Kuwahara scheme [31] in order to minimize the influence of numerical diffusion. The standard Smagorinsky model was used for the SGS model [32]. The model coefficient was assumed to be 0.1 by using a wall-damping function.

The calculation area and boundary conditions are shown in Figure 2. The horizontal calculation area is $16 \mathrm{~km}^{2}$ from the center of Ogimachi and the vertical calculation area is $5 \mathrm{~km}$. The topographic geometry data with $100 \mathrm{~m}$ horizontal spatial resolution was constructed based on the Geospatial Information Authority of Japan (GSI) with $50 \mathrm{~m}$ horizontal spatial resolution. The number of grid points to each direction is $161 \times 161 \times 51$ points in the main-flow-direction $(\mathrm{x})$, spanwise direction (y), and vertical direction (z), respectively. The grid widths of directions $\mathrm{x}$ and $\mathrm{y}$ were approximately uniform intervals, with a horizontal resolution of approximately $100 \mathrm{~m}$. The grid width was nonuniform in the $\mathrm{z}$ direction so that the density of grid points increased smoothly toward the ground surface $\left(\Delta z_{\min }=3 \mathrm{~m}\right)$. The targeted wind direction was north-northwest. The inflow boundary surface was given with a velocity profile following the $1 / 7^{\text {th }}$ power law. The upper boundary surface and the side boundary surface were given with slip conditions, and the outflow boundary surface was given with convective outflow conditions. The ground surface was given with no-slip conditions. The nondimensional parameter Re of Equation (2) is a Reynolds number $\left(=\mathrm{U}_{\text {in }} \mathrm{h} / \mathrm{v}\right)$. In the present study, the LES is assumed to reproduce the wind tunnel testing. Therefore, the effects of atmospheric stability associated with vertical thermal stratification of the atmosphere and inflow turbulence were neglected. In addition, as in Uchida [2] [14], the effects of the surface roughness were taken into consideration by reconstructing surface irregularities in high resolution. The comparison between RANS results and the present LES results are summarized in the latest article [3], and the prediction accuracy of the present LES approach by comparison with wind tunnel experiments is discussed in the article [13]. The nondimensional parameter Re was assumed to be $10^{4}$. Here, $\mathrm{h}$ is the altitude difference in the calculation domain $(h=1029 \mathrm{~m}), \mathrm{U}_{\text {in }}$ is the wind velocity at the inflow boundary surface at the height of the maximum terrain elevation within the calculation domain and $v$ is a kinematic coefficient of viscosity. The nondimensional time increment was assumed to be $\mathrm{t}=2 \times 10^{-3} \mathrm{~h} / \mathrm{U}_{\text {in }}$.

The Ogimachi and Network for Wind Measurement in Kyushu (NeWMeK) observation sites (Nos. 22 and 27) and Saga University (hereafter referred as to Saga) are shown in Figure 2. NeWMeK is a wide-area high-density wind-observation system of Kyushu Electric Co., Ltd. This system can capture the distribution characteristics of strong winds, such as the process of generation and dissipation of local winds in a wide area in real time. This system has 123 observation stations using electrical-transmission steel towers in all areas of Kyushu and can continuously and simultaneously record data in one-second 


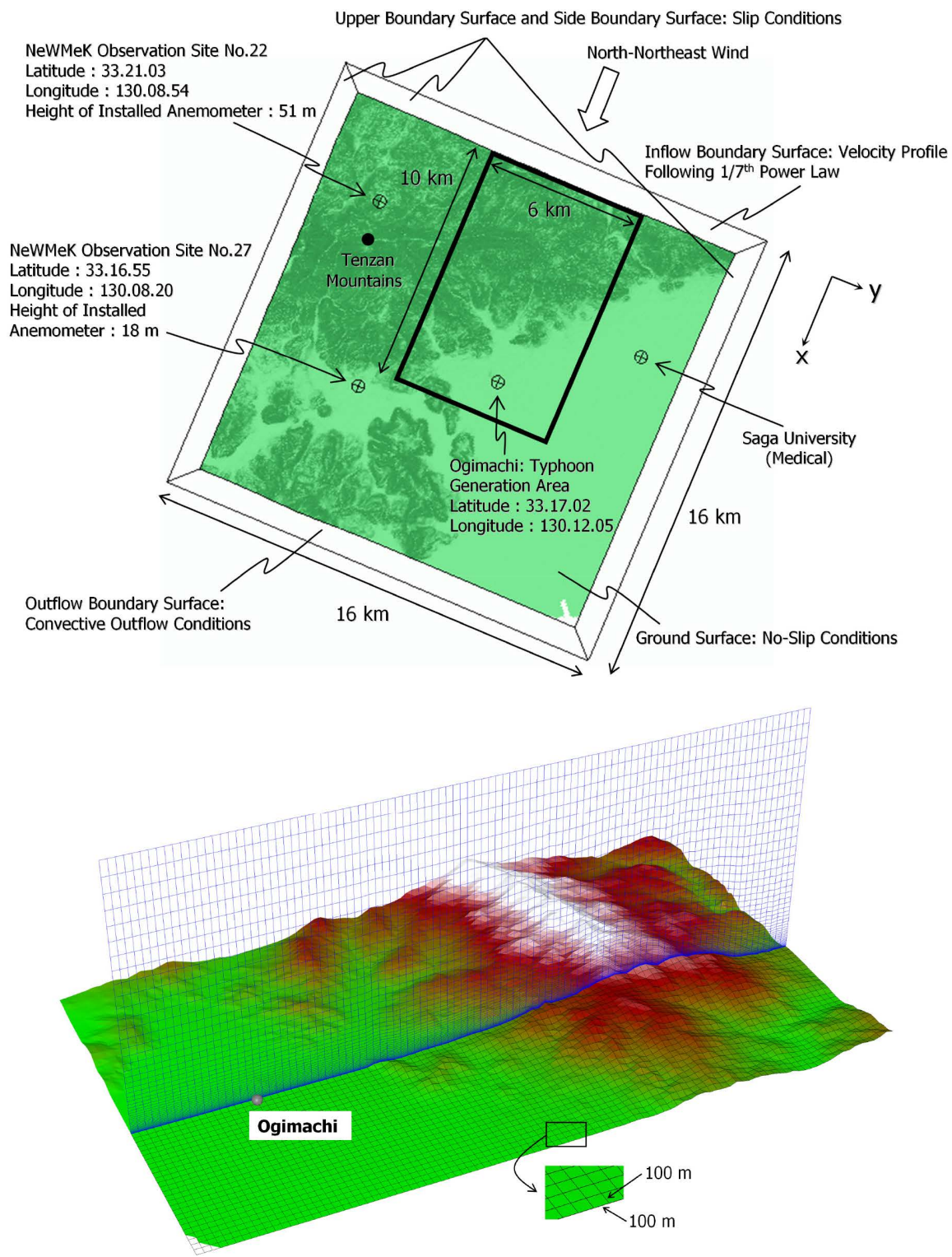

Figure 2. Calculation area, boundary conditions and computational grid.

intervals. The No. 22 and $27 \mathrm{NeWNeK}$ observation sites observed strong winds when a typhoon passed through. This is described later. Saga was used as the site for comparison with Ogimachi.

\section{Wind-Velocity Data Record When Typhoon 0423 Was Passing Through}

Table 1 shows wind-velocity data recorded at $\mathrm{NeWMeK}$ observation sites 22 and 27 at the time when Typhoon 0423 was passing through for 10 minutes, from $16: 30$ to $16: 40,20$ October 2004 . If it is taken into consideration that the anemometer of No. 27 was installed $18 \mathrm{~m}$ above the ground, it can be expected that strong winds extensively occurred near the ground during this time period. 
Table 1. Wind-velocity data recorded at the Network for Wind Measurement in Kyushu (NeWMeK) observation sites.

\begin{tabular}{ccccc}
\hline \multicolumn{5}{c}{ Recording Time: 20 October 2004, 10 minutes, from 16:30 to 16:40. } \\
\hline NeWMek & $\begin{array}{c}\text { Max. Instantaneous } \\
\text { Wind Velocity }(\mathrm{m} / \mathrm{s})\end{array}$ & Wind Direction & $\begin{array}{l}\text { Average Wind } \\
\text { Velocity }(\mathrm{m} / \mathrm{s})\end{array}$ & Wind Direction \\
\hline No. 22 $(51 \mathrm{~m})$ & 31.4 & North Northeast & 18.1 & Northeast \\
No. 27 $(18 \mathrm{~m})$ & 17.6 & North-Northeast & 10.4 & North-Northeast \\
\hline
\end{tabular}

\section{Calculation Results and Discussion}

\subsection{Visualization of Flow and Mechanism for Strong-Wind Generation}

In this section, flow visualization in the neighborhood of Ogimachi is shown, and the mechanism of strong-wind generation in the neighborhood of Ogimachi is discussed. Velocity-vector diagrams (instantaneous flow field) at $20 \mathrm{~m}$ above the ground are shown in Figure 3. Figure 3(a) and Figure 3(b) shows numerical results at different times. Figure 4 shows the contour diagram (instantaneous flow field) of the main-flow-direction $(\mathrm{x})$ velocity components corresponding to the time of Figure 3. The range of contour here is $0.6 \leq\left(\mathrm{u} / \mathrm{U}_{\text {in }}\right) \leq$ 1.3 , and this range is shown by being divided into 30 . Therefore, the areas in which contours are shown mean that they locally have stronger winds than the surrounding areas. Pay attention to Ogimachi and Saga in Figure 3. Almost no strong-wind areas were generated in the areas surrounding Saga. Contrarily, it can be found that Ogimachi had strong winds, the same as those of the areas located high above sea level on the upstream side. Furthermore, this can be clearly understood if you scrutinize it together with Figure 4, which shows that speed-increasing areas always generate in the neighborhood of Ogimachi. This was confirmed in the flow animation. What is interesting is that the local increasing-speed area extended in a stripe shape from the side of the upper stream, as shown in Figure 4 (the area surrounded with the dotted line). This suggests that speed-increasing flow is generated in the upper stream of Ogimachi, and it flows down to Ogimachi without decreasing speed.

It was clarified that the generation sources of speed-increasing areas in the surroundings of Ogimachi are in the areas indicated with the solid lines in Figure 3 and Figure 4. Therefore, this part is enlarged and shown in Figure 5. The result of superposing a streamline on the contour diagram of the main-flow-direction (x) velocity components (instantaneous flow field), shown in Figure 4, is shown in Figure 5. Pay attention to the streamline in which virtual particles are released from a height of $20 \mathrm{~m}$ above the ground and the particle trajectories are drawn. In the mountain terrain of the upper stream of Ogimachi, there is a small basin in the neighborhood of the area surrounded with solid lines. As a result, the flows converge can be captured. In other words, the strong winds in the neighborhood of Ogimachi are presumably caused because the flows of wind converge at the small basin in the mountain terrain in the 


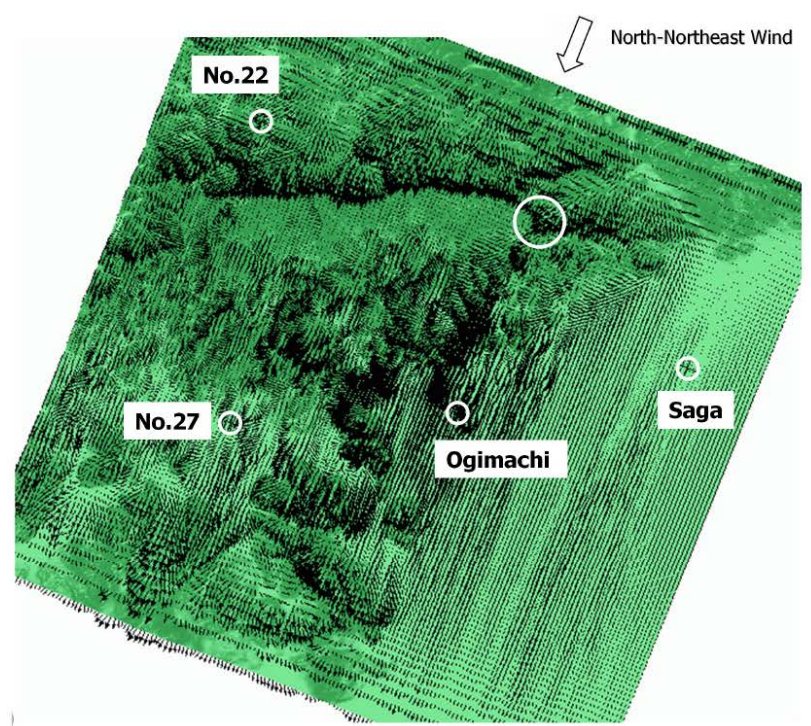

(a)

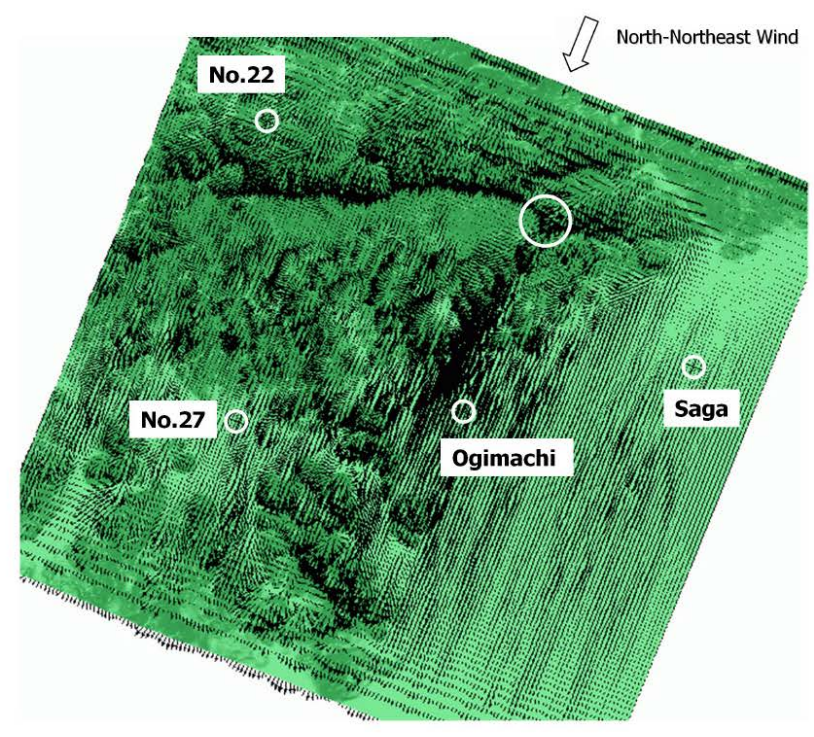

(b)

Figure 3. Velocity vector diagrams (instantaneous flow field) at $20 \mathrm{~m}$ above the ground. (a) Nondimensional time = T1; (b) Nondimensional time $=\mathrm{T} 1+\Delta \mathrm{t}$.

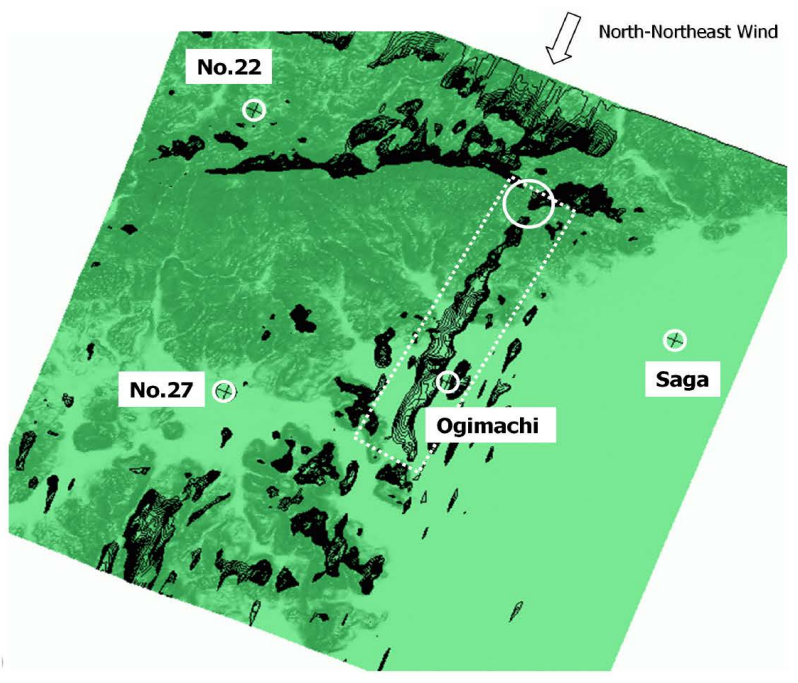

(a)

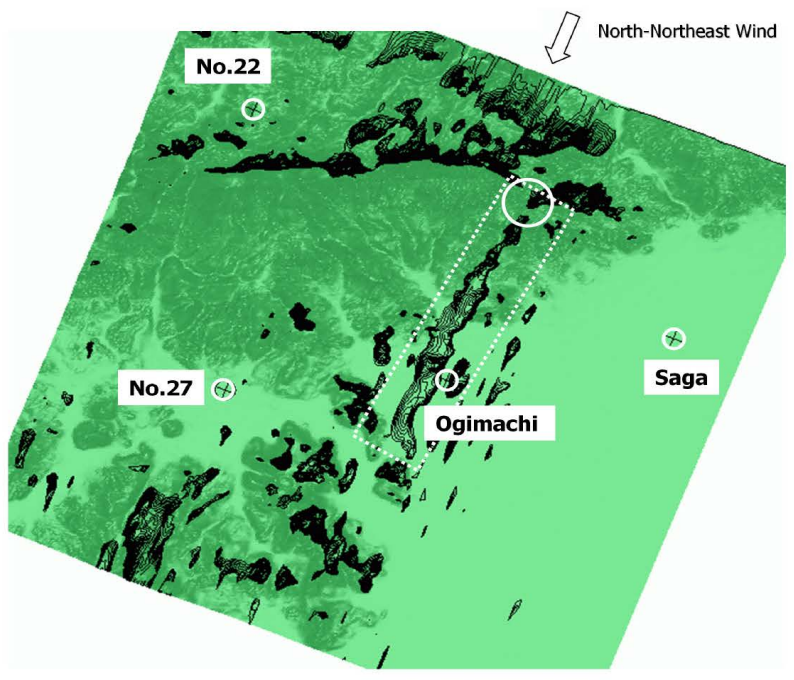

(b)

Figure 4. Contour diagram of main-stream-direction $(x)$ velocity components $20 \mathrm{~m}$ above ground. $0.6 \leq\left(\mathrm{u} / \mathrm{U}_{\text {in }}\right) \leq 1.3$ is divided into 30. (a) Nondimensional time $=\mathrm{T} 1$; (b) Nondimensional time $=\mathrm{T} 1+\Delta \mathrm{t}$.

upper stream, which leads to gap flows, so to speak. Furthermore, as shown in Figure 6, it is considered that the reason why the speed-increasing flow did not slow down so much is that the terrain (wind path) is easy for wind to go through.

\subsection{Time-History Waveform and Vertical Profile of Various Quantities of Turbulent Airflow}

In this section, more quantitative discussions are outlined. Figure 7 shows the 


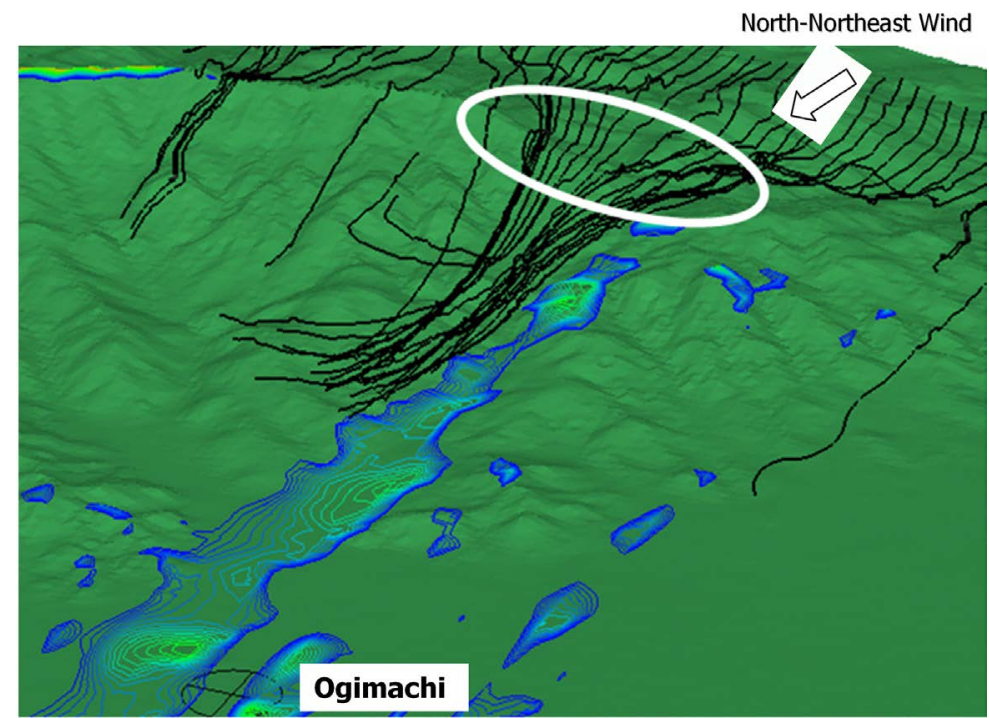

Figure 5. Streamline and contour diagram of main-stream-direction $(x)$ velocity components drawn from $20 \mathrm{~m}$ above ground. $0.6 \leq\left(\mathrm{u} / \mathrm{U}_{\text {in }}\right) \leq 1.3$ is divided into 30 .

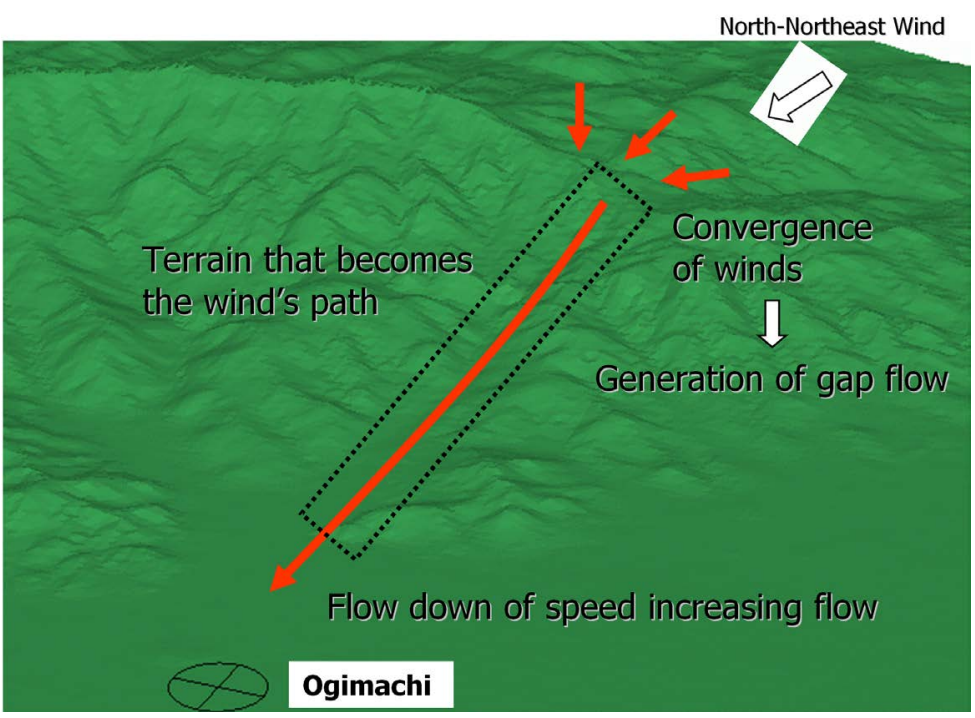

Figure 6. Mechanism of local strong winds generating in the surrounding areas of Ogimachi.

time variations ( 20 and $30 \mathrm{~m}$ above ground) of real-scale velocity components of main-flow-direction (x). For the purpose of comparison, the time-history waveform of Saga (20 and $30 \mathrm{~m}$ above ground) is also shown with it. The way to convert the nondimensional wind-velocity value that was output from the numerical simulation to a realistic scale is explained. In this calculation, wind velocities and times are normalized, as shown in Equations (3) and (4), based on the reference scales.

Normalization of Wind Velocities and Times

$$
\left.u_{i}\right|_{\text {nondimensional }}=\left.u_{i}\right|_{\text {actual scale }} / U_{\text {in }}
$$




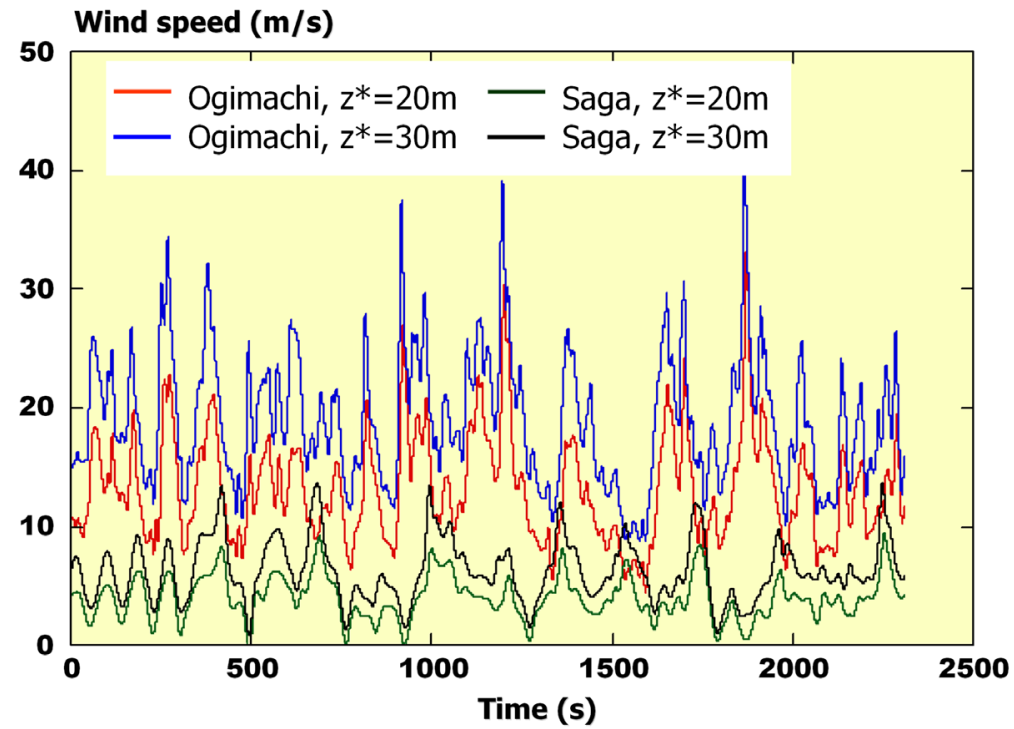

Figure 7. Time-history waveforms in real scale of main-stream-direction (x) velocity components in the points of Ogimachi and Saga.

$$
\left.t\right|_{\text {nondimensional }}=\left.t\right|_{\text {actual scale }} /\left(h / U_{\text {in }}\right)
$$

Superscript (-) to which the spatial filter was applied is omitted as a matter of convenience. In order to convert wind velocity and time to real-scale values, you only have to substitute the values of specific reference scale $h(m)$ and $U_{\text {in }}(m / s)$. As for wind velocity, $U_{\text {in }}(\mathrm{m} / \mathrm{s})$ was set so that the nondimensional average wind-velocity value corresponding to the No. 22 (51 m above ground) NeWMeK observation site coincides with the average wind velocity $(18.1 \mathrm{~m} / \mathrm{s})$ for ten $\mathrm{mi}$ nutes from 16:30 to 16:40, 20 October 2004, shown in Table 1. This was caused because it was supposed that the effects of surrounding terrains were small because the No. $22 \mathrm{NeWMeK}$ observation site is located at the side of the upper stream of the calculation area and relatively high above ground at $51 \mathrm{~m}$.

As shown in Figure 7, no high wind velocity emerged at the Saga test points from 20 to $30 \mathrm{~m}$ above ground during the weak-wind condition. On the contrary, average wind velocity from 20 to $30 \mathrm{~m}$ high above ground at the point of Ogimachi was greater than Saga. It was also observed that large wind-velocity values often emerged in the shape of a spike. Average wind velocity obtained from the time-history waveform of Figure 7 is shown in Table 2.

The average speed profile of main-flow-direction (x) and the vertical profile of standard deviation are shown in Figure 8 and Figure 9, respectively. The vertical axis is $z^{*}(\mathrm{~m})$ above ground in real scale, and the horizontal axis is a nondimensional value normalized by inflow wind velocity $U_{\text {in }}$. In Figure 9, it can be seen that the standard deviation for each mesh point is not the turbulence intensity divided by average wind velocity of that point. In both Figure 8 and Figure 9 , the position of $20 \mathrm{~m}$ above ground is shown. If you pay attention to the average velocity profile shown in Figure 8, you can notice that winds about three times stronger occur around Ogimachi than in Saga at $20 \mathrm{~m}$ above the ground. In the 
Table 2. Average values in real scale of main-flow-direction (x) velocity components in the points of Ogimachi and Saga.

\begin{tabular}{cc}
\hline Point & $\begin{array}{c}\text { Average Value }(\mathrm{m} / \mathrm{s}) \\
\text { Velocity Components }\end{array}$ \\
\hline Ogimachi, 20 m above ground & 11.8 \\
Ogimachi, 30 m above ground & 16.9 \\
Saga, 20 m above ground & 3.6 \\
Saga, 30 m above ground & 5.6 \\
\hline
\end{tabular}

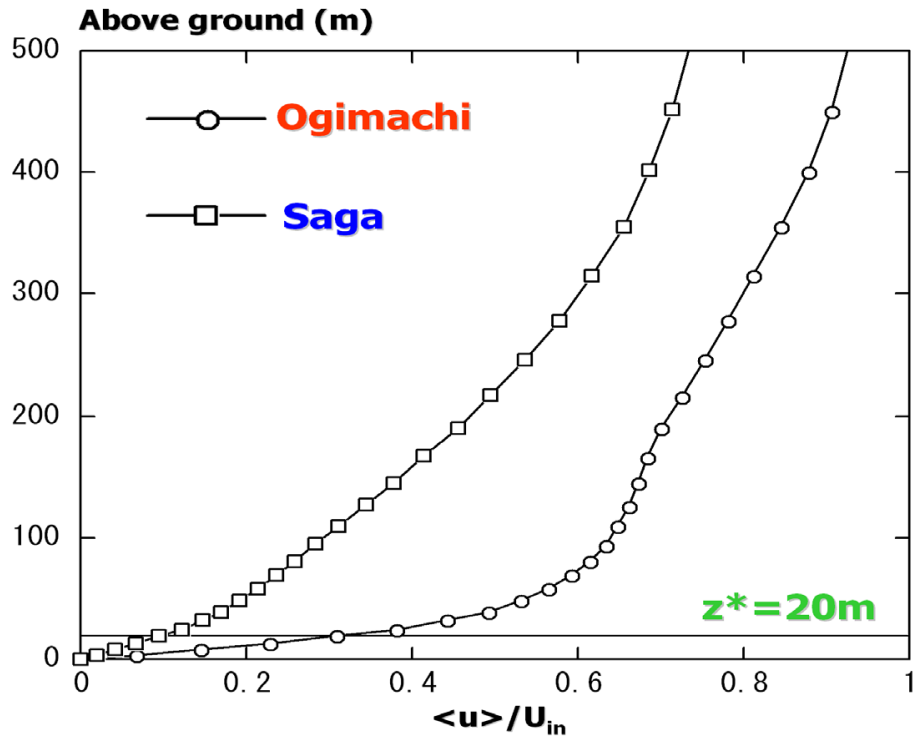

Figure 8. Average velocity profile in the points of Ogimachi and Saga, main-flow $(\mathrm{x})$ velocity components.

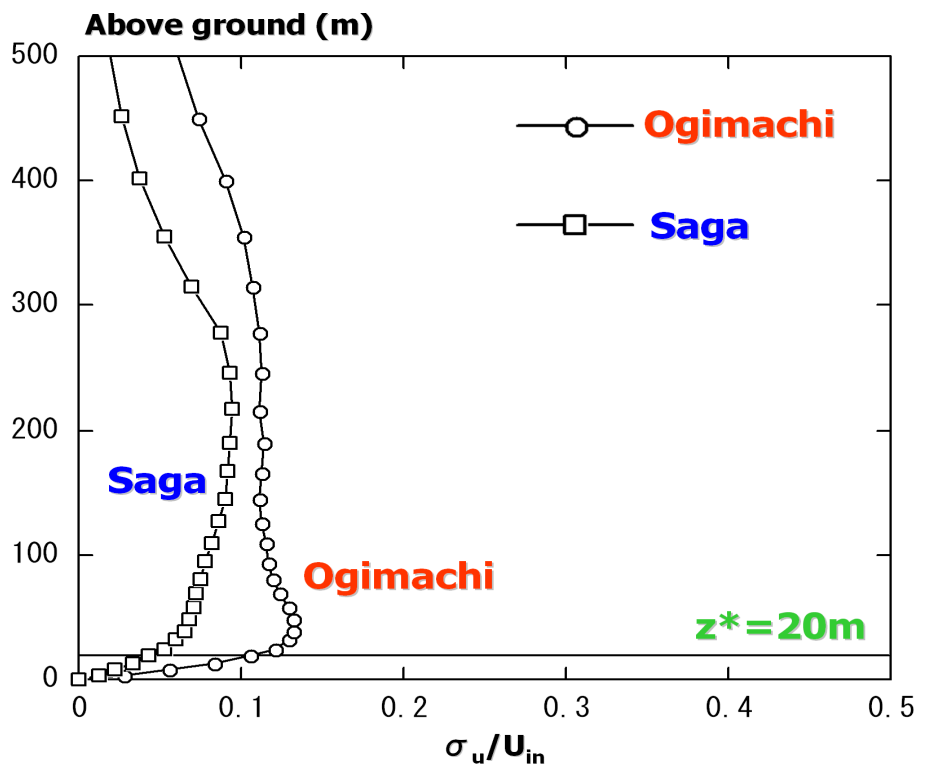

Figure 9. Vertical profile of standard deviation in the points of Ogimachi and Saga, main-flow (x) velocity components. 
vertical profile of the standard deviation shown in Figure 9, values are clearly larger in Ogimachi than those in Saga. Therefore, as mentioned in Figure 7, it became clear that greatly fluctuating and very strong winds occurred in Ogimachi.

\section{Grid-Resolution Effects}

It was shown in the previous section that subtle changes of topographic reliefs become a source of topographic wind generation (local strong wind, gap flow in this research). Therefore, in order to reproduce such flow phenomena using a numerical simulation, it is very important to clarify how accurately small terrains should be reproduced, in other words, to what extent is horizontal grid resolution required. In this research, three cases of numerical simulations with different grid dissolutions were conducted, and the above problems are discussed.

The calculation area is the area surrounded by a solid line, as shown in Figure 1. This area has a horizontal space of $10 \mathrm{~km}$ to the main-stream-direction (x), a horizontal space of $6 \mathrm{~km}$ to the orthogonal direction to the main-stream-direction (y), and a space of $4 \mathrm{~km}$ was set up in the vertical direction (z). Three cases of dissolution, shown in Table 3, are discussed. The number of meshes in the vertical direction ( $\mathrm{z}$ ) of each of the three cases is 51 , and their grid dissolutions are also the same. The first cell from the ground, the minimum mesh width, is approximately $2.4-2.5 \mathrm{~m}$.

Figure 10 shows the comparison of the reproducibility of surrounding areas of topographic-strong-wind (local-strong-wind) generation sources. No significant difference was observed between the $50 \mathrm{~m}$ horizontal grid resolution of Figure 10(a) and the $100 \mathrm{~m}$ horizontal grid resolution of Figure 10(b) (resolution by the calculation of the wide area up to the previous section). Meanwhile, the result of the $200 \mathrm{~m}$ horizontal grid resolution of Figure 10(c) shows noticeable differences in topographic reliefs compared with those of Figure 10(a) and Figure 10(b). The obtained calculation result by each grid resolution is shown below.

Figure 11 shows the contour diagram (instantaneous flow field) of the main-stream-direction ( $\mathrm{x}$ ) velocity component $20 \mathrm{~m}$ above ground. The range of the contour is shown by dividing $0.6 \leq\left(\mathrm{u} / \mathrm{U}_{\text {in }}\right) \leq 1.3$ into 30 in the same way as before. The speed-increasing flow, from a small basin of mountain terrain in the upper stream of Ogimachi, can be observed in the resolution shown in

Table 3. Grid resolutions of three discussed cases.

\begin{tabular}{lccc}
\hline & $\begin{array}{c}\text { Horizontal Grid Resolution } \\
(\Delta \mathbf{x}=\Delta \mathrm{y})\end{array}$ & $\begin{array}{c}\text { Number of Grid } \\
\text { Points } \\
(\mathrm{NX} \times \mathrm{NY} \times \mathrm{NZ})\end{array}$ & $\begin{array}{c}\text { Minimum Altitude, } \\
\text { Maximum Altitude, }\end{array}$ \\
\hline Case 1 & $50 \mathrm{~m}$ & $201 \times 121 \times 51$ & $4.0,832.0,828.0$ \\
Case 2 & $100 \mathrm{~m}$ & $101 \times 61 \times 52$ & $4.0,820.0,816.0$ \\
Case 3 & $200 \mathrm{~m}$ & $51 \times 31 \times 51$ & $4.0,801.0,797.0$ \\
\hline
\end{tabular}




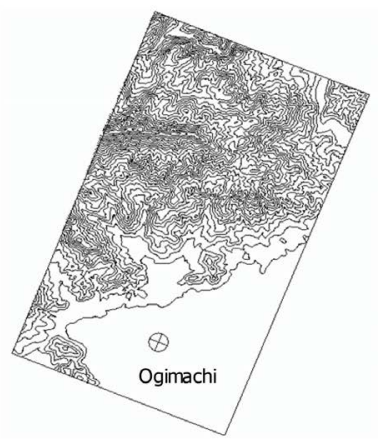

(a)

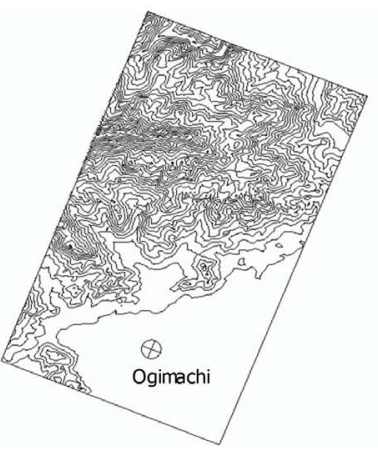

(b)

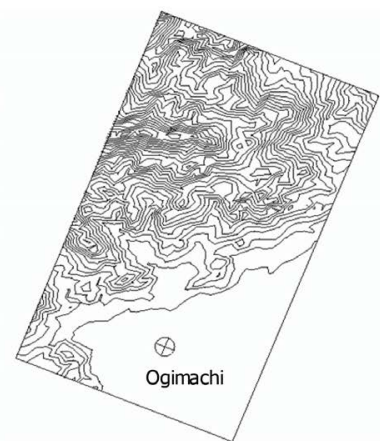

(c)

Figure 10. Comparison of terrain reproducibility. (a) Case 1, Horizontal grid resolution $50 \mathrm{~m}$; (b) Case 2, Horizontal grid resolution $100 \mathrm{~m}$; (c) Case 3, Horizontal grid resolution $200 \mathrm{~m}$.

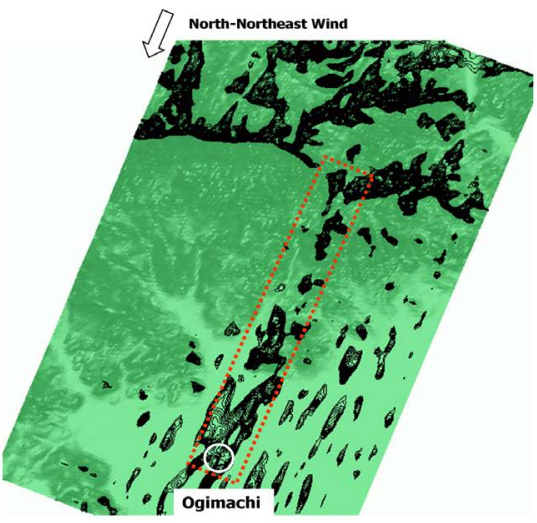

(a)

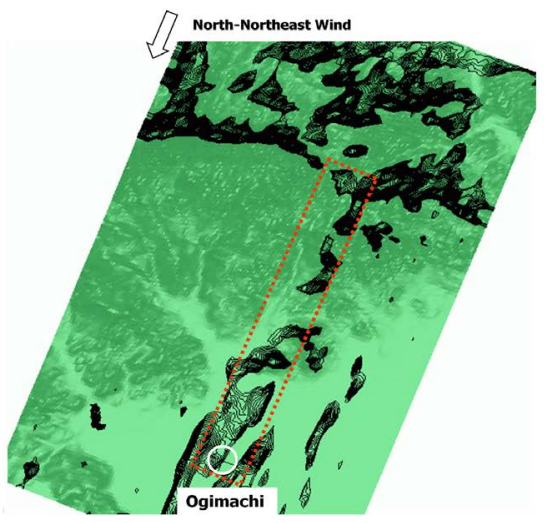

(b)

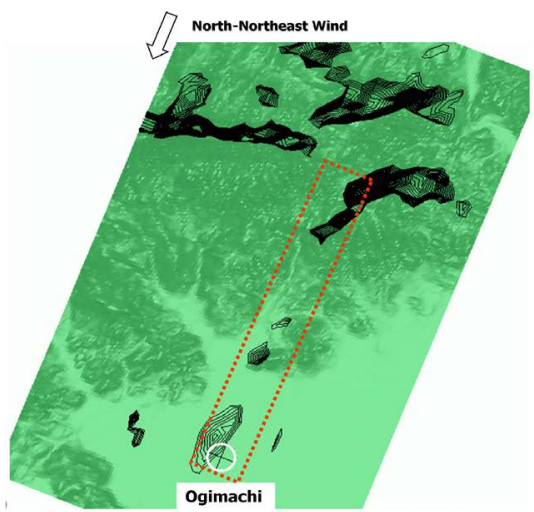

(c)

Figure 11. Contour diagram of main-stream-direction $(x)$ velocity component $20 \mathrm{~m}$ above ground. $0.6 \leq\left(\mathrm{u} / \mathrm{U}_{\text {in }}\right) \leq 1.3$ is divided into 30. (a) Case 1 , Horizontal grid resolution $50 \mathrm{~m}$; (b) Case 2, Horizontal grid resolution $100 \mathrm{~m}$; (c) Case 3, Horizontal grid resolution $200 \mathrm{~m}$.

Figure 11(a) (horizontal grid resolution; $50 \mathrm{~m}$ ) and Figure 11(b) (horizontal grid resolution; $100 \mathrm{~m}$ ), the same as Figure 4. Meanwhile, as the result of the horizontal grid resolution at $200 \mathrm{~m}$ shown in Figure 11(c), local winds from the valley were almost not reproduced. 


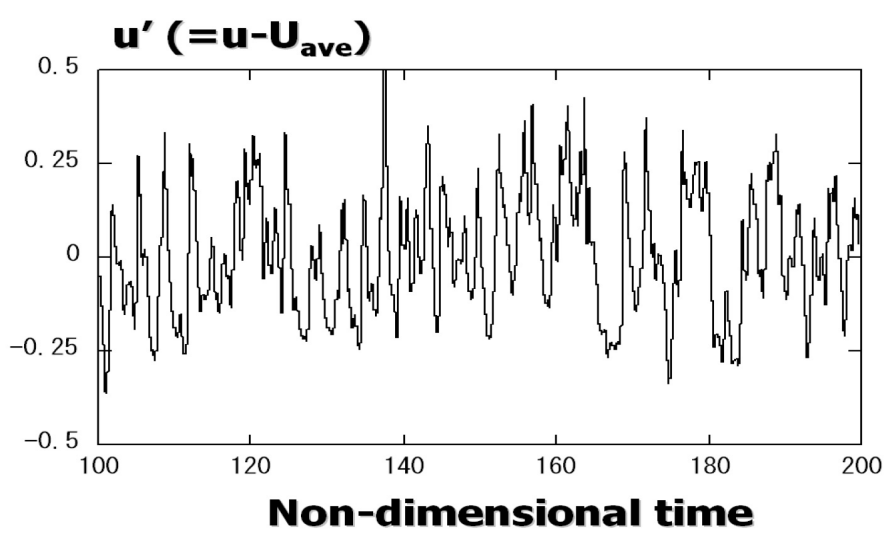

(a)

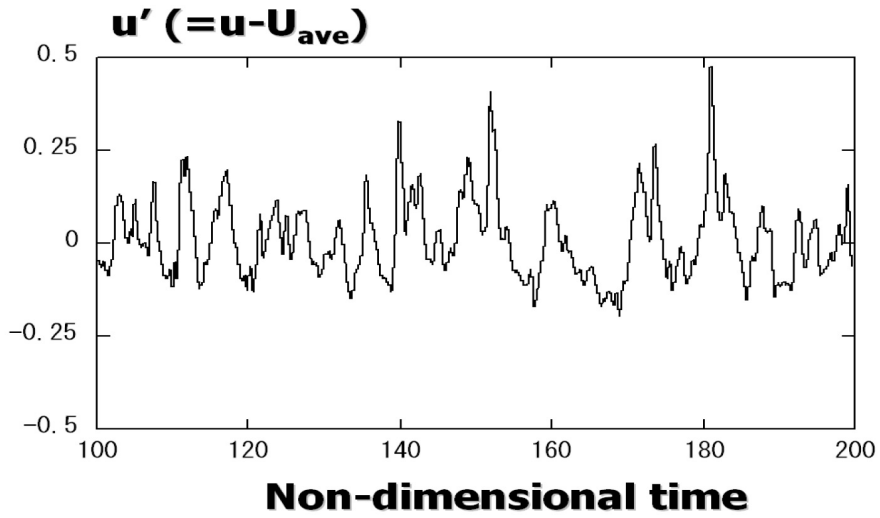

(b)

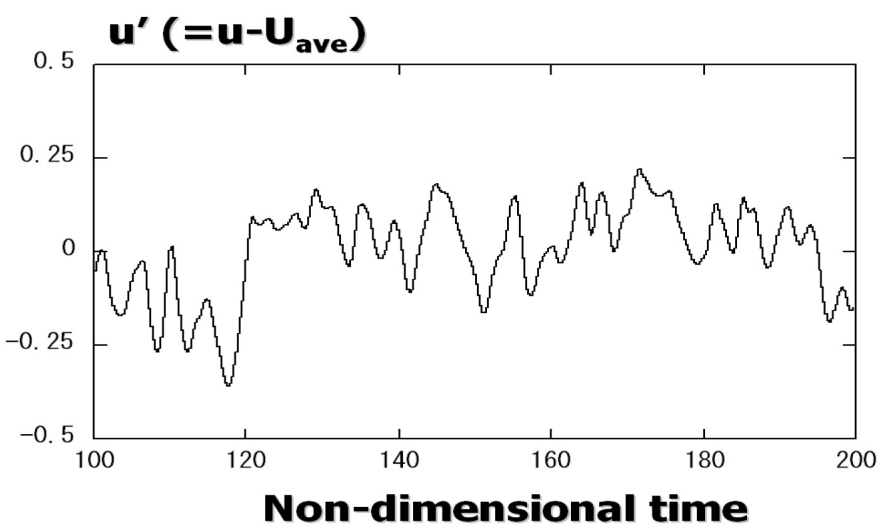

(c)

Figure 12. Time-history waveform of main-flow-direction (x) velocity component, nondimensional scale. (a) Case 1, Horizontal grid resolution $50 \mathrm{~m}$; (b) Case 2, Horizontal grid resolution $100 \mathrm{~m}$; (c) Case 3, Horizontal grid resolution $200 \mathrm{~m}$.

The effects of the grid resolution can be understood more clearly by showing the time-history waveform of the speed-variation component. Figure 12 shows the time changes of main-stream-direction $(x)$ speed-variation components, $u^{\prime}$ $\left(=\mathrm{y}-\mathrm{U}_{\text {ave }}\right)$ at $200 \mathrm{~m}$ above ground. Both the vertical and the horizontal axis are 
on a nondimensional scale. The time scale of the horizontal axis almost corresponds to the real scale of Figure 7. Large-fluctuation velocities (variable amplitudes), as shown in Figure 7, can be observed by the $50 \mathrm{~m}$ resolution shown in Figure 12(a), and the $100 \mathrm{~m}$ resolution shown in Figure 12(b). It is revealed that high-frequency components are reproduced more noticeably in the $50 \mathrm{~m}$ resolution shown in Figure 12(a) in particular, along with the increase of grid resolution. Contrarily, as a result of the $200 \mathrm{~m}$ resolution shown in Figure 12(c), almost all of the speed variations due to the passing of speed-increasing flow are not captured, but it looks like they are smoothed.

\section{Conclusions}

The mechanism of the generation of strong winds generated in Ogimachi, Saga Prefecture caused by Typhoon 0423 was investigated using a nonstationary and nonlinear wind-synopsis simulator, RIAMM-COMPACT. Furthermore, a discussion was conducted about how the difference of terrain reproducibility, grid resolution, which is required for the reproduction of these topographic strong winds, affects the calculation result. The findings obtained in this research are as follows:

1) The direction of the wind at the time when the damage was caused by Typhoon 0423 ranged from northeast to north-northwest, and it was shown that the Tenzan Mountains located in the north side of Ogimachi had an influence on that.

2) It was observed that there is a small basin in the mountain terrain in the upper stream of Ogimachi and all flows were converging there. In other words, it became clear that it is highly possible that the strong winds that were generated in the areas surrounding Ogimachi were caused by wind flows converging to a small basin of mountain terrain in the upper stream and formed a gap flow.

3) It was shown that a horizontal resolution of $50-100 \mathrm{~m}$ is required for the reproducibility of local-scale terrain.

\section{Acknowledgements}

This work is an update of the previous conference abstract [33]. The author expresses appreciation to the person concerned at that time.

\section{Funding}

This work was supported by JSPS KAKENHI Grant Number 17H02053.

\section{Conflicts of Interest}

The author declares no conflict of interest.

\section{References}

[1] Uchida, T. (2018) Large-Eddy Simulation of Airflow over a Steep, Three-Dimensional Isolated Hill with Multi-GPUs Computing. Open Journal of Fluid Dynamics, 8, 
416-434. https://doi.org/10.4236/ojfd.2018.84027

[2] Uchida, T. (2018) Numerical Investigation of Terrain-Induced Turbulence in Complex Terrain by Large-Eddy Simulation (LES) Technique. Energies, 11, 2638. https://doi.org/10.3390/en11102638

[3] Uchida, T. and Li, G. (2018) Comparison of RANS and LES in the Prediction of Airflow Field over Steep Complex Terrain. Open Journal of Fluid Dynamics, 8, 286-307. https://doi.org/10.4236/ojfd.2018.83018

[4] Uchida, T. (2018) Computational Fluid Dynamics Approach to Predict the Actual Wind Speed over Complex Terrain. Energies, 11, 1694. https://doi.org/10.3390/en11071694

[5] Uchida, T. (2018) LES Investigation of Terrain-Induced Turbulence in Complex Terrain and Economic Effects of Wind Turbine Control. Energies, 11, 1530. https://doi.org/10.3390/en11061530

[6] Uchida, T. (2018) Computational Fluid Dynamics (CFD) Investigation of Wind Turbine Nacelle Separation Accident over Complex Terrain in Japan. Energies, 11, 1485. https://doi.org/10.3390/en11061485

[7] Uchida, T. (2018) Large-Eddy Simulation and Wind Tunnel Experiment of Airflow over Bolund Hill. Open Journal of Fluid Dynamics, 8, 30-43. https://doi.org/10.4236/ojfd.2018.81003

[8] Uchida, T. (2017) Three-Dimensional Numerical Simulation of Stably Stratified Flows over a Two-Dimensional Hill. Open Journal of Fluid Dynamics, 7, 579-595. https://doi.org/10.4236/ojfd.2017.74039

[9] Uchida, T. (2017) High-Resolution LES of Terrain-Induced Turbulence around Wind Turbine Generators by Using Turbulent Inflow Boundary Conditions. Open Journal of Fluid Dynamics, 7, 511-524. https://doi.org/10.4236/ojfd.2017.74035

[10] Uchida, T. (2017) CFD Prediction of the Airflow at a Large-Scale Wind Farm above a Steep, Three-Dimensional Escarpment. Energy and Power Engineering, 9, 829-842. https://doi.org/10.4236/epe.2017.913052

[11] Uchida, T. (2017) High-Resolution Micro-Siting Technique for Large Scale Wind Farm Outside of Japan Using LES Turbulence Model. Energy and Power Engineering, 9, 802-813. https://doi.org/10.4236/epe.2017.912050

[12] Uchida, T. and Ohya, Y. (2011) Latest Developments in Numerical Wind Synopsis Prediction Using the RIAM-COMPACT ${ }^{\circledast}$ CFD Model. Energies, 4, 458-474. https://doi.org/10.3390/en4030458

[13] Uchida, T. and Ohya, Y. (2008) Micro-Siting Technique for Wind Turbine Generators by Using Large-Eddy Simulation. Journal of Wind Engineering \& Industrial Aerodynamics, 96, 2121-2138. https://doi.org/10.1016/j.jweia.2008.02.047

[14] Uchida, T. and Ohya, Y. (2006) Application of LES Technique to Diagnosis of Wind Farm by Using High Resolution Elevation Data. JSME International Journal Series $B, 49,567-575$. https://doi.org/10.1299/jsmeb.49.567

[15] Uchida, T. and Ohya, Y. (2003) Large-Eddy Simulation of Turbulent Airflow over Complex Terrain. Journal of Wind Engineering \& Industrial Aerodynamics, 91, 219-229. https://doi.org/10.1016/S0167-6105(02)00347-1

[16] Uchida, T. and Ohya, Y. (1999) Numerical Simulation of Atmospheric Flow over Complex Terrain. Journal of Wind Engineering \& Industrial Aerodynamics, 81, 283-293. https://doi.org/10.1016/S0167-6105(99)00024-0

[17] Yang, Z., Calderer, A., He, S., et al. (2019) Measurement-Based Numerical Study of the Effects of Realistic Land Topography and Stratification on the Coastal Marine 
Atmospheric Surface Layer. Boundary-Layer Meteorology, 171, 289-314. https://doi.org/10.1007/s10546-018-00423-2

[18] Yang, Z., Calderer, A., He, S., Sotiropoulos, F., Doyle, J.D., Flagg, D.D., MacMahan, J., Wang, Q., Haus, B.K., Graber, H.C. and Shen, L. (2018) Numerical Study on the Effect of Air-Sea-Land Interaction on the Atmospheric Boundary Layer in Coastal Area. Atmosphere, 9, 51. https://doi.org/10.3390/atmos9020051

[19] Gargallo-Peiró, A., Avila, M., Owen, H., Prieto-Godino, L. and Folch, A. (2018) Mesh Generation, Sizing and Convergence for Onshore and Offshore Wind Farm Atmospheric Boundary Layer Flow Simulation with Actuator Discs. Journal of Computational Physics, 375, 209-227. https://doi.org/10.1016/j.jcp.2018.08.031

[20] Murthy, K.S.R. and Rahi, O.P. (2017) A Comprehensive Review of Wind Resource Assessment. Renewable and Sustainable Energy Reviews, 72, 1320-1342. https://doi.org/10.1016/j.rser.2016.10.038

[21] Simões, T. and Estanqueiro, A. (2016) A New Methodology for Urban Wind Resource Assessment. Renewable Energy, 89, 598-605. https://doi.org/10.1016/j.renene.2015.12.008

[22] Misu, Y. and Ishihara, T. (2018) Prediction of Frequency Distribution of Strong Crosswind in a Control Section for Train Operations by Using Onsite Measurement and Numerical Simulation. Journal of Wind Engineering and Industrial Aerodynamics, 174, 69-79. https://doi.org/10.1016/j.jweia.2017.11.020

[23] Pons, O., de la Fuente, A., Armengou, J. and Aguado, A. (2017) Towards the Sustainability in the Design of Wind Towers. Energy Procedia, 115, 41-49. https://doi.org/10.1016/j.egypro.2017.05.005

[24] Fukuhara, T., Tanimoto, S. and Araki, K. (2016) Methods to Estimate Spatial Distribution of Local Meteorological Conditions along Railway Line. Quarterly Report of RTRI, 57, 268-274. https://doi.org/10.2219/rtriqr.57.4 268

[25] Araki, K., Fukuhara, T., Shimamura, T. and Imai, T. (2011) Method for Detecting Railway Line Sections Exposed to Strong Winds Using Numerical Simulations. Quarterly Report of RTRI, 52, 27-33. https://doi.org/10.2219/rtriqr.52.27

[26] Burlando, M., Freda, A., Ratto, C.F. and Solari, G. (2010) A Pilot Study of the Wind Speed along the Rome-Naples HS/HC Railway Line. Part 1-Numerical Modelling and Wind Simulations. Journal of Wind Engineering and Industrial Aerodynamics, 98, 392-403. https://doi.org/10.1016/j.jweia.2009.12.006

[27] Freda, A. and Solari, G. (2010) A Pilot Study of the Wind Speed along the Rome-Naples HS/HC Railway Line: Part 2-Probabilistic Analyses and Methodology Assessment. Journal of Wind Engineering and Industrial Aerodynamics, 98, 404-416. https://doi.org/10.1016/j.jweia.2009.12.005

[28] Takemi, T., Kusunoki, K., Araki, K., Imai, T., Bessho, K., Hoshino, S. and Hayashi, S. (2010) Representation and Localization of Gusty Winds Induced by Misocyclones with a High-Resolution Meteorological Modeling. Theoretical and Applied Mechanics Japan, 58, 121-130.

[29] Kim, J. and Moin, P. (1985) Application of a Fractional-Step Method to Incompressible Navier-Stokes Equations. Journal of Computational Physics, 59, 308-323. https://doi.org/10.1016/0021-9991(85)90148-2

[30] Kajishima, T. (1994) Upstream-Shifted Interpolation Method for Numerical Simulation of Incompressible Flows. Transactions of the Japan Society of Mechanical Engineers Series B, 60, 3319-3326. (In Japanese) https://doi.org/10.1299/kikaib.60.3319 
[31] Kawamura, T., Takami, H. and Kuwahara, K. (1986) Computation of High Reynolds Number Flow around a Circular Cylinder with Surface Roughness. Fluid Dynamics Research, 1, 145-162. https://doi.org/10.1016/0169-5983(86)90014-6

[32] Smagorinsky, J. (1963) General Circulation Experiments with the Primitive Equations. Part 1, Basic Experiments. Monthly Weather Review, 91, 99-164. https://doi.org/10.1175/1520-0493(1963)091<0099:GCEWTP>2.3.CO;2

[33] Uchida, T. and Ohya, Y. (2007) Numerical Simulation of Local Strong Wind Induced by Topographic Effect. The Proceedings of the Fluids Engineering Conference, Hiroshima, 17 November 2007. (In Japanese) 